\title{
Effect of Zn Doping on Structural and Some Optical Studies of Nano NiO Films Prepared by Sol-Gel Technique
}

\author{
Foaad Sh. Hashim, Noor A. Sami \\ University of Babylon, College of Education for Pure Science, Iraq \\ E-mail address: bur11111@yahoo.com E-mail: noormaster89@yahoo.com
}

Keywords: NiO:Zn, Thin Film, Sol-Gel Spin Coating Technique

\begin{abstract}
ABSTACT. This research deals with the study of the structural andoptical properties of $\mathrm{NiO}$ and $\mathrm{Zn}$ doped $\mathrm{NiO}$ nano films with different ratios $(0.01,0.05,0.1 \mathrm{~mol} \%)$. NiO nano films in thickness $100 \mathrm{~nm}$ were deposited on a glass substrate using sol-gel spin coating technique. XRD results indicated that the films are polycrystalline and have cubic structure with a preferred orientation along (111). The average grain sizes of the crystallites estimated from XRD data was found to lie in the range of $19.11-25.05 \mathrm{~nm}$. Data of AFM indicate that the surface of films is smooth.The optical transmittance value of nano $\mathrm{NiO}$ film reaches to $94 \%$ in the VIS and NIR regions, while it is value of films deposited with $0.1 \mathrm{~mol} \% \mathrm{Zn}$ reaches to $(91) \%$ which is important for its applications as window layers in solar cells. The values of optical energy gap of $\mathrm{NiO}$ and $\mathrm{Zn}$ doping by $0.01,0.05$, and $0.1 \mathrm{~mol} \%$ were equal to 3.73 , and $3.58,3.42,3.41 \mathrm{eV}$ respectively.
\end{abstract}

\section{INTRODUCTION}

$\mathrm{NiO}$ is an important antiferromagnetic p-type of semiconductor and is a promising candidature for many applications such as lithium ion batteries, solar cells, antiferromagnetic layer, electrochemical capacitors, chemical sensors, and electrochromic coatings [1]. Stoichiometric NiO at R.T is an insulator with a resistivity of $10^{13} \Omega \mathrm{cm}$. The electrical conductivity of $\mathrm{NiO}$ can be manipulated by changing the concentration of $\mathrm{Ni}$ ion during doping [2]. Nickel oxide has demonstrated excellent properties such as catalytic [3], magnetic ,electrochromic ,optical and electrochemical properties [4]. Znic is a first transition element in group 2 . It has a hexagonal crystal system and the structure type of hexagonal close packed with $\mathrm{a}=0.22 \mathrm{~nm}$ and $\mathrm{c}=0.49 \mathrm{~nm}$ and has an electron canfiguration of [ $\mathrm{Ar}]\left(1 \mathrm{~s}^{2} 4 \mathrm{~s}^{2}\right)$. Zinc is hard and brittle at most temperature, but malleable at 100 to $150^{\circ} \mathrm{C}$, above $210^{\circ} \mathrm{C}$ becomes brittle again[5] on the other hand, it's a fair conductor of electricity, and burns in air at high red heat with evolution of white clouds of the oxide. It is employed to form numerous alloy with other metals, alsolarge quantities of zinc are used to produce die casting, used extensively by the automotive, electrical and hardware industries[6] .we have prepared thin films from undoped $\mathrm{NiO}$ and $\mathrm{Zn}$ - doped $\mathrm{NiO}$ using sol-gel spin coating technique. The effects of $\mathrm{Zn}$ doping on the structure and some optical properties of $\mathrm{NiO}$ films were studied.

\section{EXPERIMENTAL WORK}

\subsection{Preparation of films}

Nickel oxide solution were prepared from $\mathrm{NiCl}_{2} 6 \mathrm{H}_{2} \mathrm{O}$ with purity $98 \%$. $9.5 \mathrm{~g}$ of $\mathrm{NiCl}_{2} 6 \mathrm{H}_{2}$ Owith $0.4 \mathrm{M}$ was dissolved into $100 \mathrm{ml}$ of ethanol, mixed slowly for $1 \mathrm{hr}$ by using magnetic stirrer device, and then added glycerene a rate $10 \mathrm{~V} / \mathrm{V} \%$, to obtain homogeneous solution, mixed it slowly for $6 \mathrm{hr}$ until we get way a green solution. The completed preparation of the solution by adding $0.01 \mathrm{M}$ of $\mathrm{ZnCl}_{2}$ solution for different concentrations as shown in the Table (1). 
Table 1: The rastes and concentrations of doped nickel oxide solution

\begin{tabular}{|c|c|c|c|c|c|}
\hline Rank & $\begin{array}{c}\mathrm{NiCL}_{2} 6 \mathrm{H}_{2} \mathrm{O} \\
(\mathrm{ml})\end{array}$ & $\begin{array}{c}\mathrm{NiCL}_{2} 6 \mathrm{H}_{2} \mathrm{O} \\
(\mathrm{M})\end{array}$ & $\begin{array}{c}\mathrm{ZnCL}_{2} \\
(\mathrm{ml})\end{array}$ & $\begin{array}{c}\mathrm{ZnCL}_{2} \\
(\mathrm{M})\end{array}$ & $\begin{array}{l}\mathrm{Zn} \\
(\mathrm{mol} \%)\end{array}$ \\
\hline 1 & 5 & 0.4 & 0.02 & 0.01 & 0.01 \\
\hline 2 & 5 & 0.4 & 0.1 & 0.01 & 0.05 \\
\hline 3 & 5 & 0.4 & 0.2 & 0.01 & 0.1 \\
\hline
\end{tabular}

he spin coater device was used to prepare the films under the conditions of speed $3000 \mathrm{rpm}$ and time $60 \mathrm{sec} .100 \mu \mathrm{l}$ from the solution dropped on the substrate to get a films, then dried it in electrical oven at $200{ }^{\circ} \mathrm{C}$ for $5 \mathrm{~min}$ in order to remove the effect of the solvent (Ethanol). . The samples were annealed at $500^{\circ} \mathrm{C}$ for $2 \mathrm{hr}$ in a furnace. Fig. 1 showsflow chart of NiO:Zn synthesis and the structural and optical measurements.

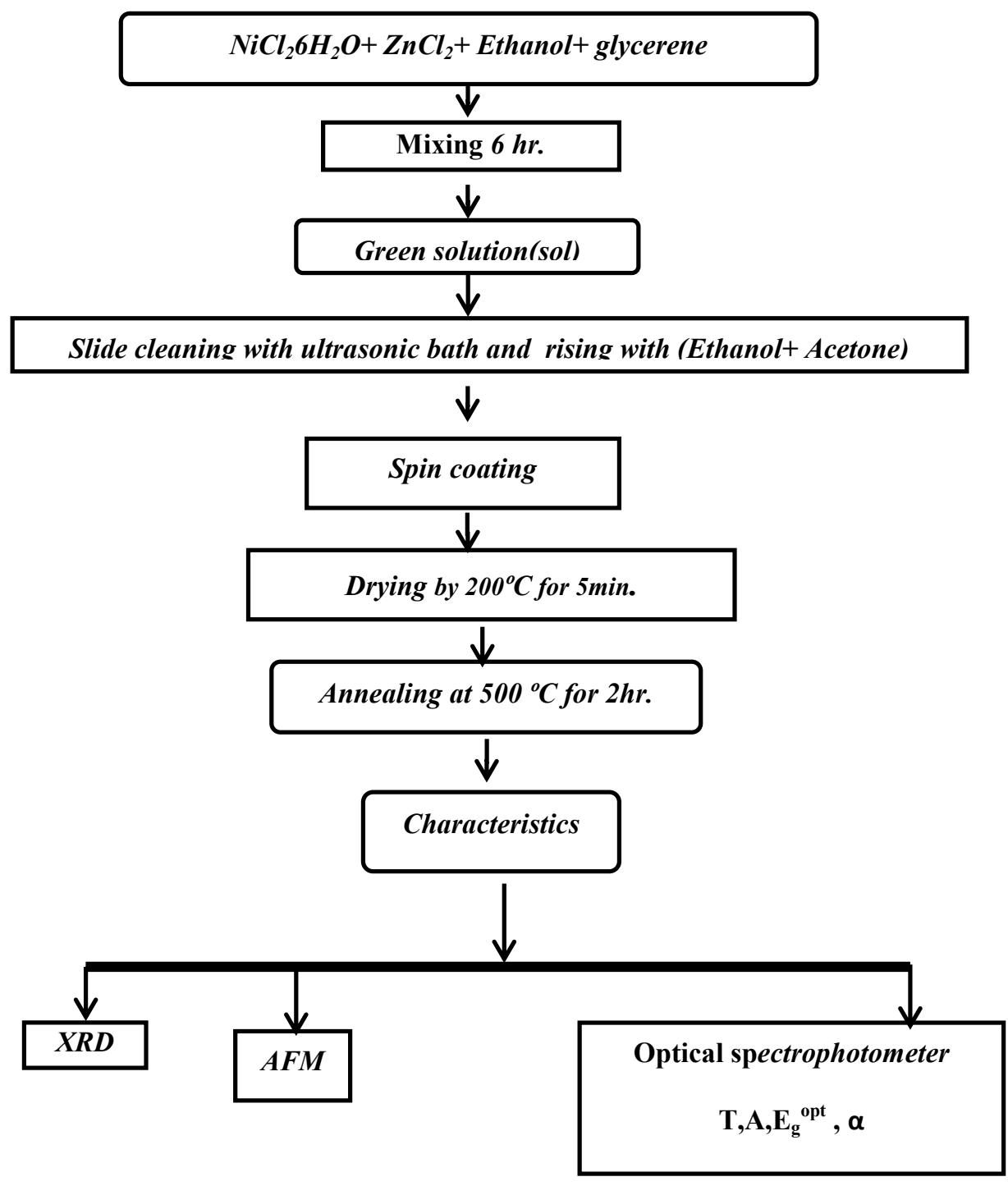

Fig. 1: Flow chart of NiO:Zn synthesis and the structural and optical measurements.

The film crystallinity was examined by X-ray diffraction 6000 of $1.54 \AA$ from Cu-k $\alpha$, the XRD patterns of samples were recorded in the range $2 \theta=20-80^{\circ}$. Surface morphologies were analyzed by an atomic force microscope AFM (AA3000, Angstrom Advanced IncUSA). We measured spectral 
absorbance and transmittance over the spectral range of $300-800 \mathrm{~nm}$ by using UV-Visible-NIR spectrophotometer supplied by Shimadzu company .

\subsection{Basic relations}

The lattice constant(a ) are estimated from the relation[7]:

$$
d=\frac{a}{\sqrt{h^{2}+k^{2}+l^{2}}}
$$

The average grain size dimension (D), can be estimated using Scherrer's formula [8].

$$
D_{a v}=\frac{0.94 \lambda}{B \cos \theta}
$$

Where: $\theta$ is the Bragg diffraction angle, $B$ is the full width of the diffraction line at half-maximum intensity (FWHM, radian).

From the crystallite size calculations calculated the dislocation density $(\delta)$ by using the relation [9]:

$$
\delta=1 / \mathrm{D}^{2} \text { av }\left(\text { line } / \mathrm{cm}^{2}\right)
$$

The number of crystallites per unit area $(\mathrm{N})$ of the films was determined by the using formula [10]:

$$
N=t / D_{a v}^{3}
$$

At the absorption edge, the absorption coefficient $(\alpha)$ can be calculated using the expression [11]:

$$
\alpha=\frac{1}{d} \ln \frac{1}{T}
$$

Where $\mathrm{d}$ is the samples thickness .

The optical energy gap $\left(\mathrm{E}_{\mathrm{g}}{ }^{\text {opt }}\right)$ was calculated using the Tauc relation which is given by the formula [12]:

$$
\alpha h v=A\left(h v-E_{g}^{o p t}\right)^{n}
$$

Where $\mathrm{n}$ is an integer depending on the nature of electronic transitions. For the direct allowed transitions $n$ has a value of $1 / 2$, while for the indirect allowed transitions $n=2$, and $A$ is energy dependent constant. $\mathrm{h}$ is Plank's constant and $h v$ is the energy of the incident photon, $v$ is the frequency.

\section{RESULTS AND DISCUSSION}

\subsection{Structural studies}

XRD patterns of the films deposited at a glass substrate temperature 298K, and thicknesses consistently around $100 \mathrm{~nm}$ are shown in Fig.2. NiO and $\mathrm{Zn}$ doped $\mathrm{NiO}$ nano films were found to be polycrystalline in nature with two diffraction peaks along with (111) and (200) planes of cubic $\mathrm{NiO}$ phase (ASTM card 04-0835).The XRD data showed the dominating peak is (111), which is found to be in agreement with the researchers Anwer, Hao and Khansaa [13,14,15]. The average grain sizes of the crystallites for major reflex(111) increase gradually with the increase of $\mathrm{Zn}$ 
concentrations. It is found to be $19.11 \mathrm{~nm}, 23.51 \mathrm{~nm}, 24.79 \mathrm{~nm}$, and $25.05 \mathrm{~nm}$ for doping concentrations $(0,0.01,0.05$, and $0.1 \mathrm{~mol}) \%$ of $\mathrm{Zn}$ respectively.

Having no reflection peaks in the spectrum of XRD which indicate the presence of $\mathrm{Zn}$. The diffraction peaks of samples $\mathrm{NiO}$ doped with concentration $0.01,0.05$, and $0.1 \mathrm{~mol} \%$ of $\mathrm{Zn}$ are slightly shifted towards lower $2 \theta$ values (diffraction peaks of (111) emerged at $2 \theta$ degree of 37.43 and $37.31,37.28,37.27$ for pure $\mathrm{NiO}$ and $0.01,0.05$, and $0.1 \mathrm{~mol} \mathrm{\%}$ of $\mathrm{Zn}$-doped $\mathrm{NiO}$ respectively) in comparison with peaks for $\mathrm{NiO}$ as shown in Fig.2, resulting from the distortion (in the form of swelling) that has plagued the basic lattice attributed to the ionic radius of $\mathrm{Zn} \mathrm{(0.083}$ $\mathrm{nm})$ compared with that values of $\mathrm{Ni}(0.078 \mathrm{~nm})$ [16].

The lattice parameters, dislocation density and number of crystallites per unit area of undopedNiO and $\mathrm{Zn}$ doping by $0.01,0.05$ and $0.1 \mathrm{~mol} \%$, were calculated using equation $(1,3,4)$.

Table 2: Values of lattice constant, dislocation density and the no. of crystallite per unit area

\begin{tabular}{c|c|r|c|c|}
\cline { 2 - 5 } & Rank & $\begin{array}{r}\text { Lattice constant a } \\
(\mathrm{nm})\end{array}$ & $\begin{array}{c}\text { Dislocation density } \\
\delta \text { lines/ } \mathrm{cm}^{2}\end{array}$ & $\begin{array}{c}\text { Number of crystallites unit } \\
\text { area }\end{array}$ \\
\hline 0.4171 & 0 & 0.4171 & 2.70985 & 1.4106455 \\
\hline 0.4175 & 1 & 0.4175 & 1.809234 & 7.695593 \\
\hline 0.4177 & 2 & 0.4177 & 1.627222 & 6.639014 \\
\hline 0.4181 & 3 & 0.4181 & 1.593619 & 6.361753 \\
\hline
\end{tabular}
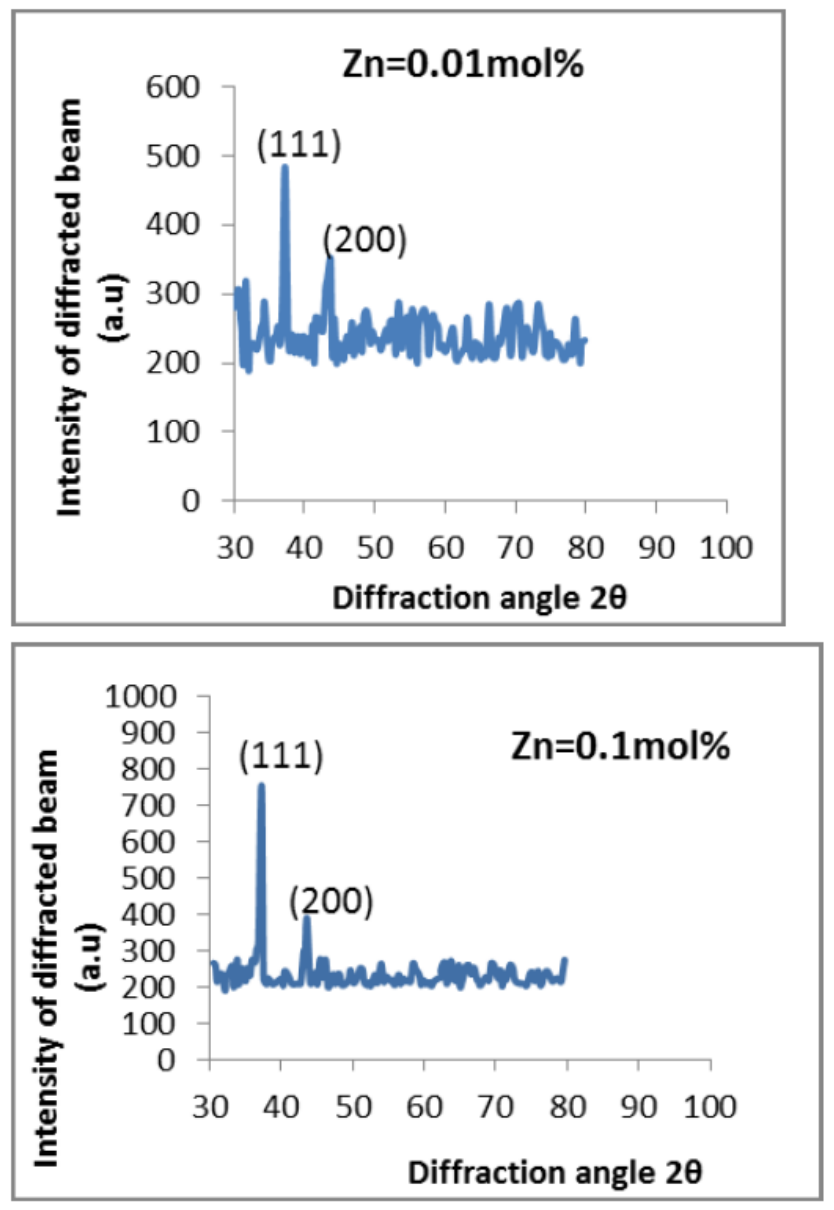

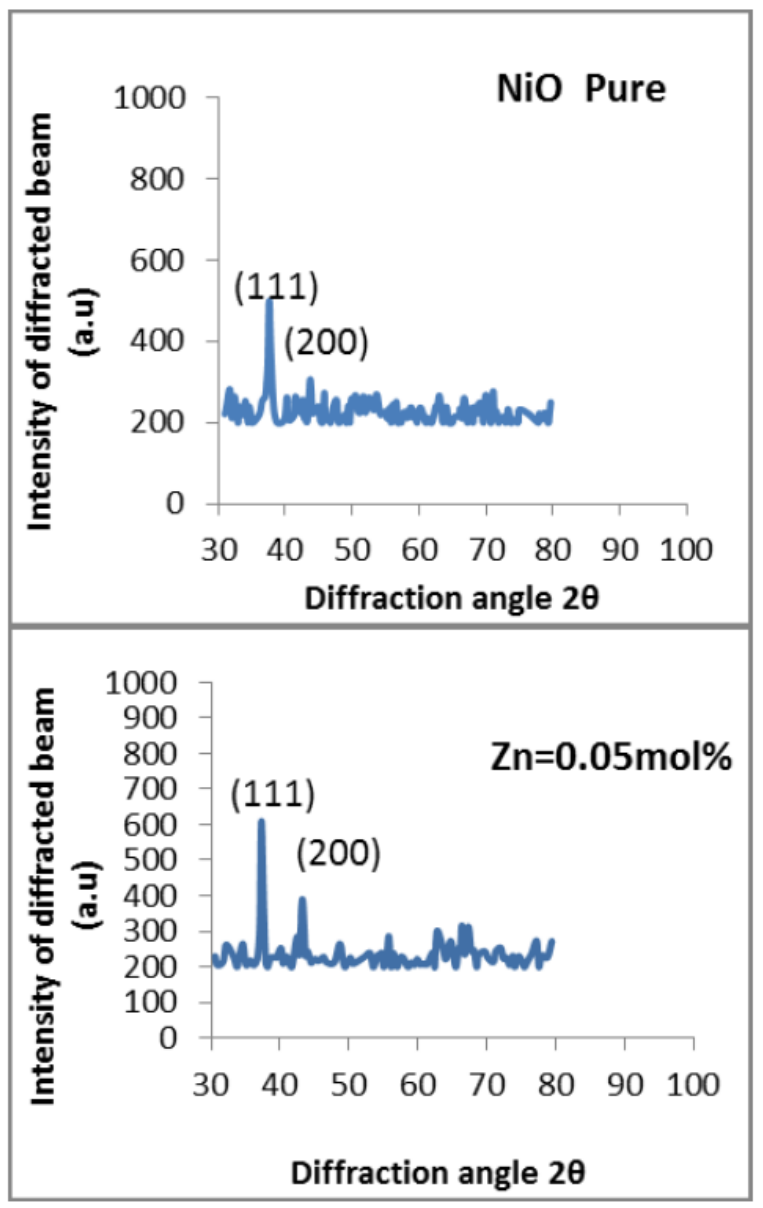

Fig. 2: XRD patterns of $\mathrm{NiO}$ and $\mathrm{NiO}$ : $\mathrm{Zn}$ doped thin films at different concentration 


\subsection{Surface Morphological Studies}

The surface morphology of undoped $\mathrm{NiO}$ and $\mathrm{Zn}$ doping by $0.01,0.05$ and 0 . $1 \mathrm{~mol} \%$,was studied measured at thickness of 100nm,It was observed with AFM micrographs as shown in Fig.3. It can be notice that a root mean square (RMS) roughness ranged of 6.06-4.82 nm, and a maximum peak to peak height, Sz (ten point height) ranged of 23.9 -20.4 $\mathrm{nm}$. Data above indicate that the surface of films is highly smooth as can be seen from the results listed in Table 3.

$2 \mathrm{D}$

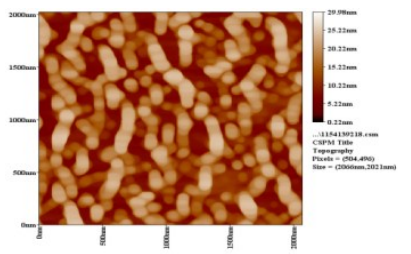

2D

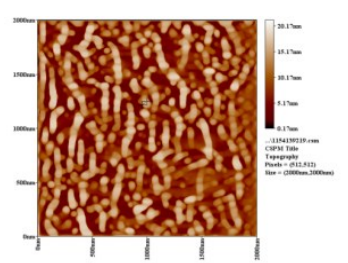

$2 \mathrm{D}$

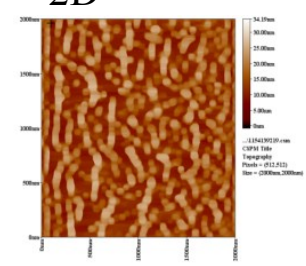

$2 \mathrm{D}$

NiO: $0.01 \mathrm{~mol} \% \mathrm{Zn}$

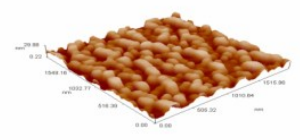

$3 \mathrm{D}$

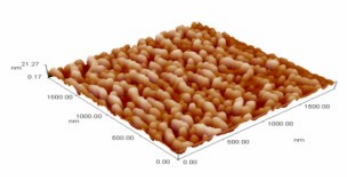

NiO: $0.05 \mathrm{~mol} \% \mathrm{Zn}$

$3 \mathrm{D}$

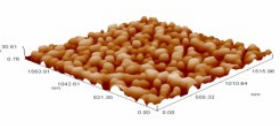

NiO: $0.1 \mathrm{~mol} \% \mathrm{Zn}$

$3 \mathrm{D}$

Fig. 3: AFM images for undoped $\mathrm{NiO}$ and various $\mathrm{Zn}$-doped $\mathrm{NiO}$ films. (-1- for $2 \mathrm{D}$, \& -2- for 3D)

Table 3: AFM data for undoped $\mathrm{NiO}$ and various $\mathrm{Zn}$-doped $\mathrm{NiO}$ films measured at thickness of $100 \mathrm{~nm}$ films .

\begin{tabular}{|l|l|l|l|}
\hline $\begin{array}{l}\text { Concentration } \\
\text { Of } \mathrm{Zn}(\%)\end{array}$ & $\begin{array}{l}\text { Roughness } \\
\text { average } \\
\text { Sa(nm) }\end{array}$ & $\begin{array}{l}\text { Root } \\
\text { mean } \\
\text { square } \\
\text { Sq(nm) }\end{array}$ & $\begin{array}{l}\text { Ten } \\
\text { point } \\
\text { height } \\
\text { Sz(nm) }\end{array}$ \\
\hline $\mathbf{0}$ & 5.24 & 6.06 & 23.9 \\
\hline $\mathbf{0 . 0 1}$ & 4.67 & 5.31 & 10 \\
\hline $\mathbf{0 . 0 5}$ & 3.99 & 4.59 & 9.2 \\
\hline $\mathbf{0 . 1}$ & 4.22 & 4.82 & 20.4 \\
\hline
\end{tabular}

\subsection{Some Optical Studies}

\subsubsection{Absorbance}

Fig. 4 shows the dependence of absorbance on the wavelength $(\lambda)$ in the spectral range 300-800 $\mathrm{nm}$ for $\mathrm{NiO}$ and $\mathrm{Zn}$-doped $\mathrm{NiO}$ nano films measured at thicknesses consistently around $100 \mathrm{~nm}$. It is clear that the absorption edges shift to longer wavelength (red shift), which is indicating a decrease in the optical band gap value, with respect to the increasing of $\mathrm{Zn}$ concentration. This is attributed to the presence of intra band transitions at localized states in the energy gap. The sharp 
absorption edge; corresponding to the band gap confirms the good quality of grown films. The films show higher absorption on the shorter wavelength side (UV region), and low absorption on the higher wavelength side (VIS region).This behavior can be explained as follows: at high wavelength, the incident photon does not have enough energy to interact with atoms, thus the photon will be transmitted, while at low wavelength region, the incoming photons have sufficient energy to excite electrons from the valence band to the conduction band, and thus these photons are eventually absorbed within the material.

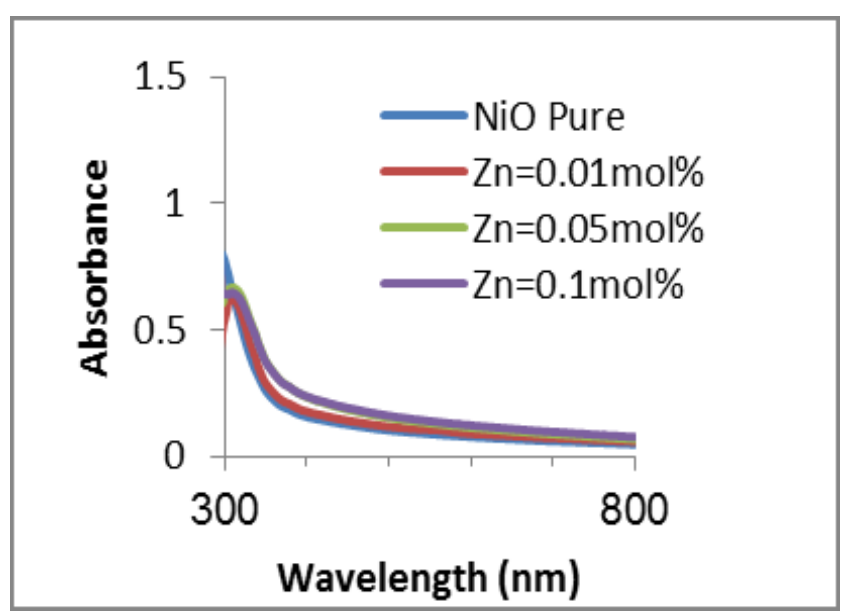

Fig. 4: Optical absorbance VS. wavelength for NiO and various Zn-doped NiO nano films.

\subsubsection{Transmittance}

Fig.5 shows the dependence of the optical transmittance on the wavelength $(\lambda)$ in the spectra range 300-800 $\mathrm{nm}$ for $\mathrm{NiO}$ and $\mathrm{Zn}$-doped $\mathrm{NiO}$ nano films. The optical transmittance value of nano NiO film reaches to $94 \%$ in the VIS and NIR regions, while it is value films deposited with $0.1 \mathrm{~mol} \% \mathrm{Zn}$ reaches to $(91) \%$ which is important for its applications as window layers in solar cells This behavior may be attributed to microstructural features of prepared films, as the photon scattering increases by crystal defects [17]

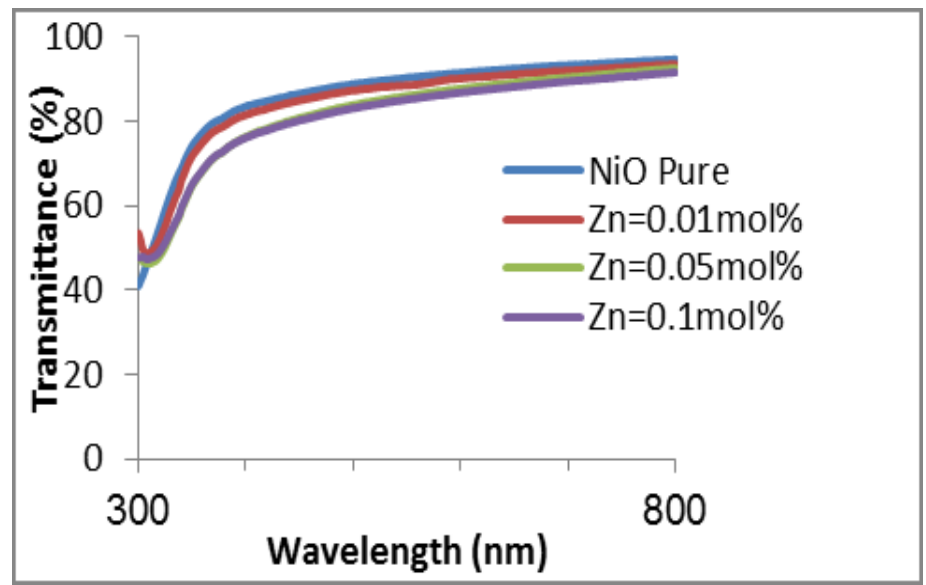

Fig. 5: Optical transmittance spectra VS wavelength for $\mathrm{NiO}$ and various $\mathrm{Zn}$-doped $\mathrm{NiO}$ nano films.

\subsubsection{Optical absorption coefficient}

Fig. 6 shows the dependence of optical absorption coefficient $(\alpha)$ on the photon energy $(\mathrm{h} v)$ for $\mathrm{NiO}$ and $\mathrm{Zn}$-doped $\mathrm{NiO}$ nano films. The optical absorption coefficient values increases with the increase of $\mathrm{Zn}$-concentration, based on the fact that a small increase in the values of absorbance was found when increasing the dopant.In the high absorption region all films have value of $\alpha>10^{4} \mathrm{~cm}^{-}$ ${ }^{1}$, which caused the increase of the probability of the occurrence of direct transition. 


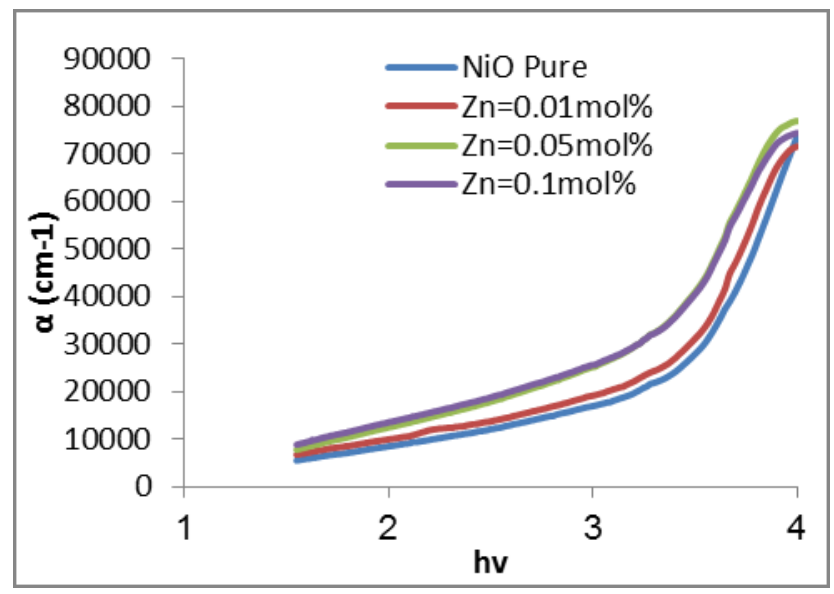

Fig 6: The absorption coefficient for $\mathrm{NiO}$ and various $\mathrm{Zn}$-doped $\mathrm{NiO}$ nanofilms .

\subsubsection{Optical energy gap $\left(\mathbf{E}_{\mathrm{g}}{ }^{\text {opt }}\right)$}

The experimental values of $(\alpha h v)^{2}$ plotted against $(\mathrm{h} v)$ of pure $\mathrm{NiO}$ and $\mathrm{NiO}: 0.01,0.05$, and $0.1 \mathrm{~mol}$ $\% \mathrm{Zn}$ concentration deposited at $298 \mathrm{~K}$ for $60 \mathrm{sec}$ and thickness consistently around $100 \mathrm{~nm}$ are shown in Fig. (4.7,a,b,c, and d). The band gap energy is determined from the extrapolated straight line portion of the plot to the $\mathrm{x}$ axis, $(\alpha \mathrm{h} v)^{2}=0$. The linear nature of the plots at the absorption edge confirmed that all deposited nano films $\mathrm{NiO}$ and $\mathrm{NiO}: \mathrm{Zn}$ are a semiconductor with direct band gap. The values of optical energy gap, which have been obtained by extrapolating the curves to $(\alpha \mathrm{h} v)^{2}=0$ for $\mathrm{NiO}$ and $\mathrm{NiO} 0.01,0.05,0.1 \mathrm{~mol} \% \mathrm{Zn}$ films were equal to 3.73 , and $3.58,3.423 .41$ $\mathrm{eV}$ respectively. Change in the optical band gap energy with concentration may be attributed to the changes in homogeneity and density of the localized states, which increases with increasing concentration of $\mathrm{Zn}$ in the deposited films.

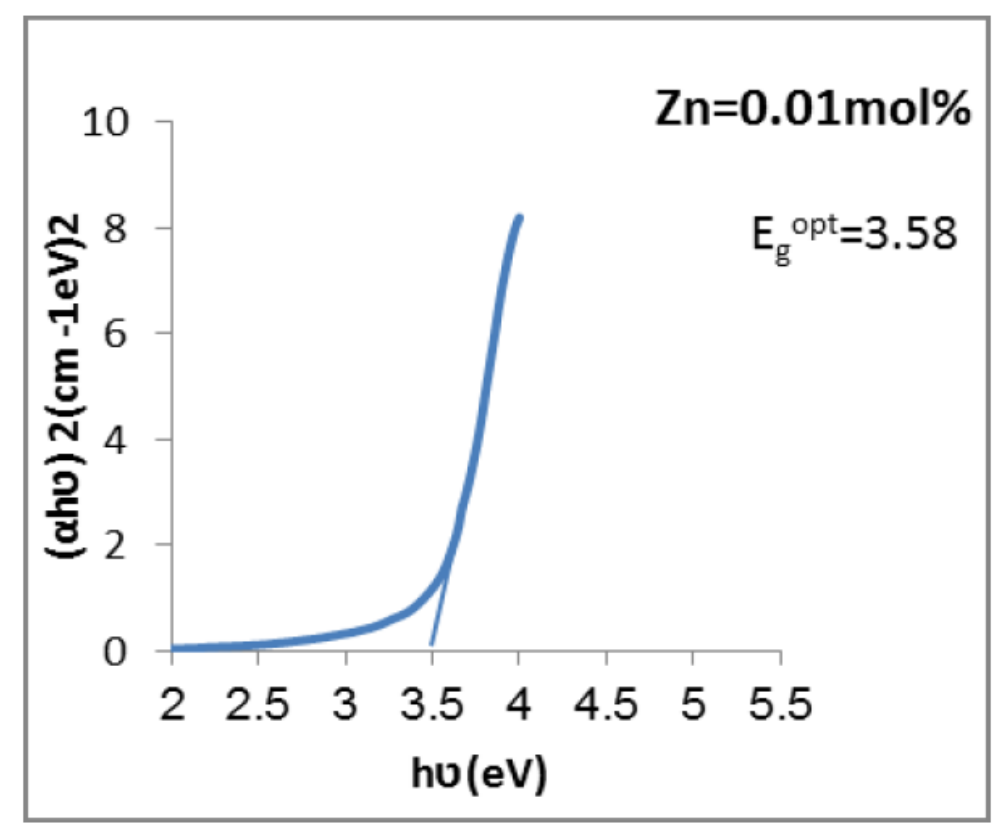

Fig. (7,a): Plot of $(\alpha h v)^{2}$ VS. photon energy (hv) for NiO film 


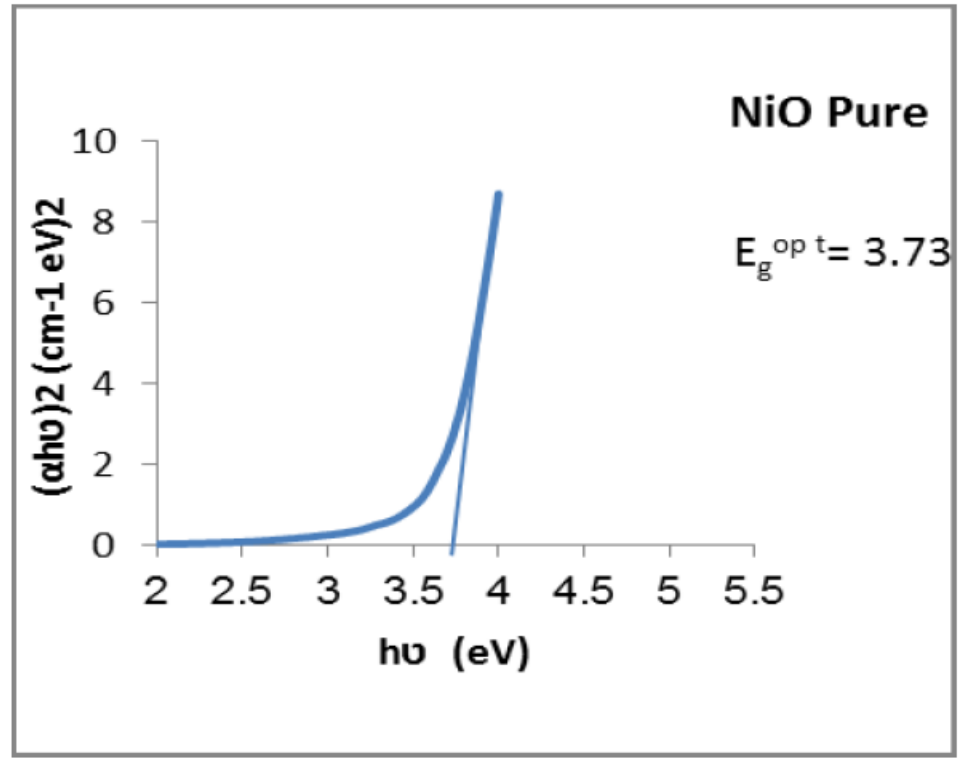

Fig. (7,b): Plot of $(\alpha h v)^{2}$ VS. photon energy (hv) for $0.01 \mathrm{~mol} \% \mathrm{Zn}$ - doped NiO film .

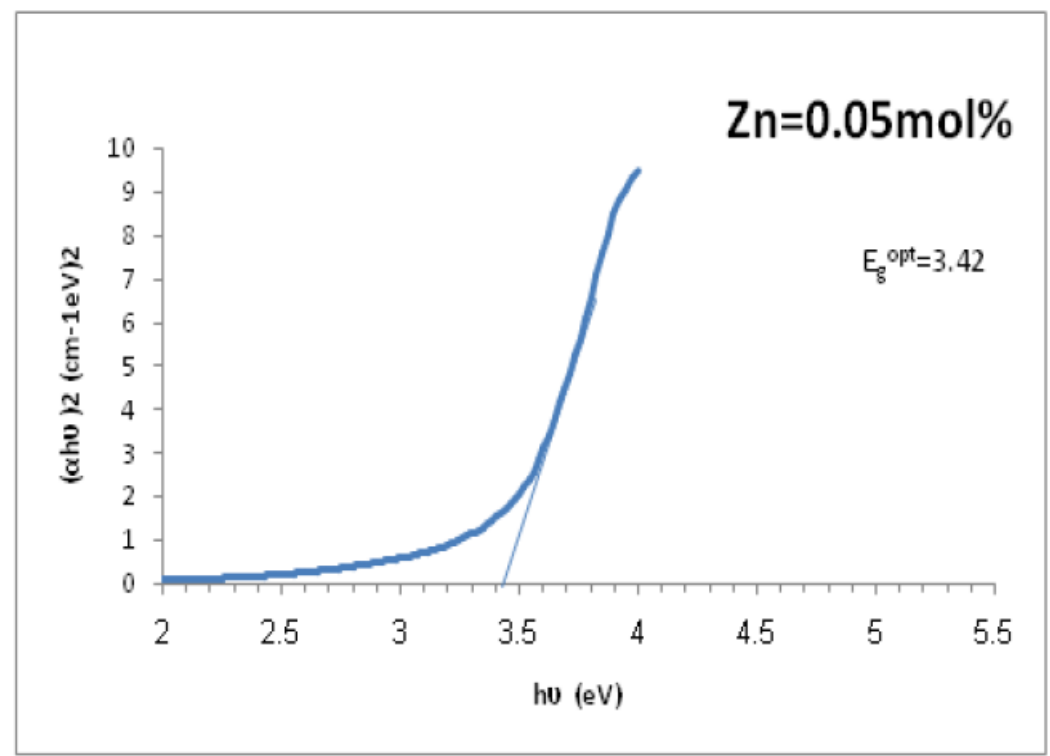

Fig. (7,d): Plot of $(\alpha h v)^{2}$ VS. photon energy (hv) for 0.1 mol \% Zn- doped NiO films. 


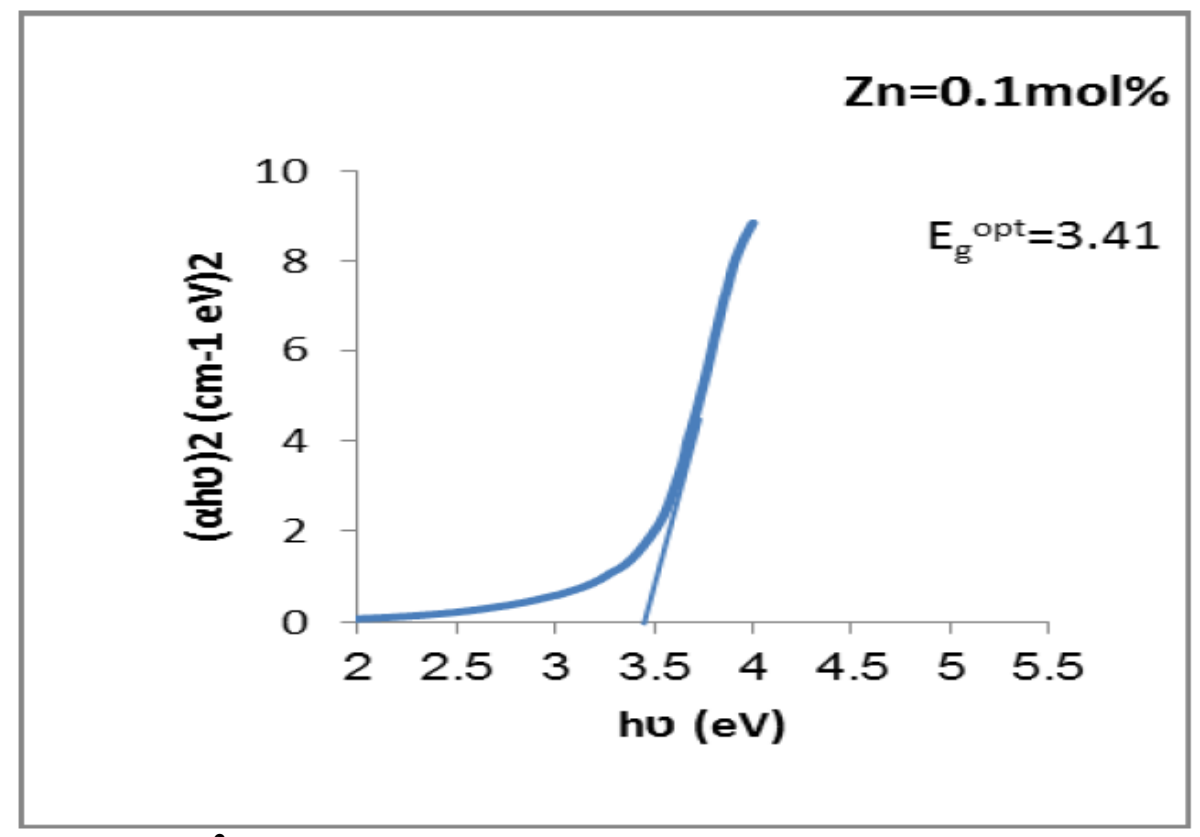

Fig. (7,c): Plot of $(\alpha h v)^{2}$ VS. photon energy (hv) for $\mathrm{NiO} 0.05 \mathrm{~mol} \% \mathrm{Zn}$ - doped $\mathrm{NiO}$ film.

\section{CONCLUSIONS}

The XRD resuls revealed that $\mathrm{NiO}$ and $\mathrm{NiO}: 0.01,0.05$, and $0.1 \mathrm{~mol} \% \mathrm{Zn}$ nano films were found to be polycrystalline and have cubic structure.The XRD data showed the dominating peak is (111). .The AFM results revealed that the surface of films is highly smooth .With increase $\mathrm{Zn}$ content an the roughness of film surface decreases. The transmittance value of undoped $\mathrm{NiO}$ film reaches to $94 \%$ in the visible and NIR range, which is important for its applications as window layers in solar cells. The optical energy gap of $\mathrm{NiO}$ with concentration $(0,0.01,0.05$, and 0.1$) \%$ of $\mathrm{Zn}$ thin films were equal to $3.73,3.58,3.42$, and $3.41 \mathrm{eV}$.

\section{References}

[1] B.T. Rauta, S.G. Pawar, M.A. Chougule, ShashwatiSenb, V.B. Patil, "New process for synthesis of nickel oxide thin films and their characterization"Jour. of Alloys and Compounds 509 (2011) 9065-9070

[2] Wen Guo, K.N. Hui, K.S. Hui, Mater. Lett. 92 (2013) 291.

[3] Y.Wang, J.Zhu, X.Yang, L.Lu, X.Wang, Thermochim.Acta 437(2005)106.

[4] X.Wang,J.Song,L .Gao, J.Jin, H.Zheng, Z.Zhang, Nanotechnology 16 (2005)37.

[5 ] Scoffern and John, " The useful metal and their alloy" ,Houlson and Wright, (2009) 591- 603.

[6] D. R. Lide, " Handbook of chemistry and physics ",CRC press, (2004).

[7] Y. SIROTINAND M. SHASKOLSKAYA, "Fundamentals of Crystal Physics" (Mir Publishers, Moscow 1982).

[8] Nano Science instruments, on the site "http://www.nanoscience. com/education/AFM.html".

[9] S. Gopal, B. Karunagaran, Sa. K. Narayandass, D. Mangalaraj and Junsin Yi, "Cryst. Res. Technol.", No. 6, p 557, (2005).

[10] T. Mahalingam 1, V. Dhanasekaran, R. Chandramohan, and Jin-Koo Rhee," Microstructural properties of electrochemically synthesized ZnSe thin films", Journal of Material Science, Vol. 47, pp. 1950-1957, (2012).

[11] Ortega M., Santana G., andAcevedo A.M., Superficies Vacio,1999,9: 294 - 295. 
[12] S. M. Sze and Kwok K. Ng," Physics of Semiconductor Devices", $3^{\text {rd }}$,Ed. John Wiley \& Sons, New York,(2007).

[13] Anwar H.Ail, Raania R.Kadhim, " Effect of copper doping on the some physical properties of Nio thin films prepared by chemical spray pyrolysis" , International Journal of Application or Innovation in Engineering \& Management 4,2319-4847 (2015).

[14] Hao-Long Chen, Yang-Ming Lu and Weng-Sing Hwang "Thickness dependence of electrical and optical properties of sputtered Nickel oxide films", Science Direct 514, 361-365 (2006)

[15] Khansai H. "Structural and optical properties of undoped and doped NiO by lithium prepared by sol-gel method" M.Sc, Babylon University (2015 )

[16] R. A. Flinn and P. K. Trojan , "Engineering materials and their applications" , Houghton Mifflin company ,Boston , (1975) .

[17] Amit Kumar Srivastava, SubhashThota, and Jitendra Kumar "Preparation, Microstructure and Optical Absorption Behaviour of NiO Thin Films", Journal of Nanoscience and Nanotechnology. 89, 4111-4115, (2008). 